\title{
ENERGY FROM DOMESTIC REFUSE BY ENZYMATIC DEGRADATION OF CELLULOSIC FIBRE WASTE INTO SUGARS AND ETHANOL: INITIAL LABORATORY STUDIES
}

\author{
Peter Randerson \\ Brian Dancer \\ Cardiff University, United Kingdom
}

\begin{abstract}
The search for commercially viable biogenic sources of transport fuel, such as ethanol, is now a priority among developed countries. Sugar- and starch-containing crops currently support mature industries producing ethanol by yeast fermentation. The potential of bulk plant materials (biomass crops, agricultural wastes and domestic refuse) is enormous, but such ligno-cellulosic compounds are difficult to degrade into simple sugar molecules. In the USA and Canada, commercial development programmes are under way to develop new enzymatic and fermentation technologies and to reduce process costs.
\end{abstract}

We investigated the potential of processed waste material derived from domestic refuse as a source of simple sugars for conversion to ethanol. "Pure" cellulose was almost completely degraded to reducing sugars by cellulase $\mathrm{C} 013 \mathrm{~L}$, a mixed enzyme preparation, and by Trichoderma viride cellulase, whereas enzymes from other fungal species performed less well. $T$. viride achieved less than $10 \%$ (by weight) conversion of waste material to reducing sugars in 2 hour incubations, whereas C013L cellulase gave sugar yields of up to $35 \%$. Extended incubation times gave little increase in yield. These results support the feedstock potential of this material. Alternative techniques, such as pre-treatment with ferulic acid esterase to improve the effectiveness of degradation, are discussed.

\section{KEYWORDS}

Ethanol; Refuse-derived waste; Ligno-cellulose degradation; Cellulase; Ferulic acid esterase

\section{INTRODUCTION}

In the UK, as in other developed countries, energy policy aims to balance environmental acceptability with energy security, at an affordable price. The government publication (2003) "Our Energy Future - Creating a Low carbon Economy" [1] defines a strategic vision for energy policy combining our environmental, security of supply, competitiveness and social goals. The UK is no longer self-sufficient in gas, and oil reserves are dwindling rapidly [2]. Our obligations under the Kyoto accord require real reductions in $\mathrm{CO}_{2}$ emissions in the near future. To do this we must reduce our dependence on gas, oil and coal by substitution with renewable. carbon-neutral fuels. Progress so far has been mostly through electricity generation by wind (both onshore and offshore); there are now 1429 turbines in the UK, with 
a total capacity over $1300 \mathrm{MW}$ [3]. However, electricity from all renewable sources was only $3.6 \%$ of the UK total in 2004, against a government target of $10 \%$ by 2010 . Another strand for $\mathrm{CO}_{2}$ reduction, in which little progress has so far been made, is energy conservation in domestic. commercial and industrial buildings.

\subsection{Biomass and waste}

Biomass from energy crops (e.g. willow coppice and Miscanthus), agricultural residues (e.g. straw and food processing waste), forestry residues, industrial waste (sawdust and process wood-waste), and the organic portion of municipal solid waste (MSW or refuse), has so far had little impact in the UK as regards energy production. In contrast in Europe, for example in Austria and Sweden, a mix of public and private investment in wood fuel technologies for domestic, commercial/industrial heating, and CHP schemes, has given rise to a raft of energyrelated industries. Three power stations constructed in the 1990s in eastern England under the Non-Fossil Fuels Obligation (a subsidy scheme for green electricity), utilise straw and chicken litter [4]. They range in size between 12 and $38 \mathrm{MW}$ and now accept locally grown Miscanthus as fuel. Biomass from SRC and waste sawdust is currently used for co-firing with coal, for example at Ferrybridge (Yorkshire), Tilbury (London), Didcot (southern England) and Aberthaw (Wales) in power stations between 1000 and $2000 \mathrm{MW}$ in size [5]. The Renewables Obligation Order (2002) has encouraged the use of biomass by creating tradable Certificates (ROCs) which provide, in effect, a subsidy of $£ 30 / \mathrm{MWh}$ for electricity from wood-fuels. Co-firing is seen as the most effective way of initiating an energy crop production infrastructure in the UK. RWE n-power recently contracted ESD Biomass to supply over 30,000 tonnes/year of SRC for Didcot power station and agreements with local growers and landowners are now being made [5]. Although wood-fuel crops such as shortrotation willow coppice are regarded as carbon-neutral, their impact in $\mathrm{CO}_{2}$ reduction depends on their being a direct substitute for fossil fuel combustion. Additional carbon costs may arise in transporting, drying and processing the crop prior to its conversion to energy.

A high proportion of MSW consists of biomass, which could provide over $40 \mathrm{TWh} / \mathrm{year}$ of "renewable" electricity in the UK [2], but energy is recovered from only $9 \%$ of MSW. Refuse-derived-fuel (RDF) is successfully used in several European countries, but there are only 4 such plants in the UK [6]. For example at Byker (Newcastle), RDF pellets are incinerated in a CHP system, which generates $2.3 \mathrm{MW}$, but this project has suffered from dioxin emissions and the technology is considered to be too costly. Alternatively, MSW can be converted into methane biogas by anaerobic digestion, either in existing landfill sites or in large-scale digesters, usually together with sewage sludge. Such AD technology is well established in continental Europe and, with pressure from rising landfill tax charges, it is now recognised as a significant market opportunity in the UK.

\subsection{Transport fuel - ethanol from crops and waste}

The use of ethanol as a motor fuel is as old as the model-T Ford, but recently has gained economic importance as a high-octane enhancer and oxygenater that reduces air pollution and improves automobile performance. Brazil pioneered the mass-production of ethanol from sugar cane by yeast fermentation in the 1980s [7]. The industry suffered from fluctuations in world prices of both sugar and oil, but recovered in 2004 with the development of "flex-fuel" cars, rising petrol costs and "green" taxation. In the USA, more than $12 \%$ of motor gasoline sales are now ethanol-blended fuels. Over $5000 \mathrm{M}$ litres/year of ethanol are produced from the starchy grains in crops such as corn and grain sorghum, largely in the corn States of the mid-west. Converting starch to sugar and ethanol is a mature technology, which is unlikely to 
undergo further cost reduction. Development projects and pilot plants in the USA and Canada currently focus on the ligno-cellulosic portion of agricultural residues such as corn stover (stalks), bagasse (sugar cane residue) and rice husks, paper waste, and food processing waste. After separation of recyclables and inert solids, MSW is also a feedstock for fuel ethanol production and is regarded as potentially profitable in view of its negative cost relative to disposal in landfill [8]. $60 \mathrm{MM}$ dry tonnes/year of corn stover is produced in the US corn States, enough to produce over 15,000 M litres/year of ethanol [9]. Iogen Corp (Ottawa) produces over $3 \mathrm{M}$ litres/year of cellulose ethanol from wheat, oat and barley straw in its demonstration plant, and the US Dept of Energy has awarded over $\$ 30 \mathrm{M}$ in grants for commercial developments. Genencor and Novozymes have research projects aimed at reducing enzyme cost (recently fallen from almost $\$ 20$ to $\$ 1 /$ litre), and to increase enzyme life and durability [10]. With advances in pre-treatment technology, fermentation processes, collection and storage logistics production of cellulose ethanol in "bio-refineries" is set to become economically feasible in the near future.

\section{CONVERSION PROCESSES FOR BIOMASS-TO-ETHANOL}

Conversion of biomass and organic waste into ethanol requires three stages:

- Pre-treatment (e.g. with dilute or concentrated halogen acids),

- Hydrolysis (enzymatic: saccharification) to degrade the material to simple sugars,

- Biological fermentation to produce ethanol.

The enzymatic and fermentation processes may take place sequentially (Separate Hydrolysis and Fermentation, SHF), or they may be combined (Simultaneous Saccharification and Fermentation, SSF). The main structural components of plant biomass are:

- Cellulose ( $40 \%-60 \%$ by weight, depending on the biomass source) is a polymer (polysaccharide) of glucose, a 6-carbon sugar (see Figure 1). In plant cell walls cellulose occurs in both crystalline regions (polymer strands lie parallel, linked by hydrogen bonds), and amorphous, non-crystalline regions [11]. Only in the noncrystalline regions can cellulase enzymes readily break the links between successive glucose units along the chain. Little overall degradation is possible unless the multistranded structure is first "loosened" to enable enzyme penetration. Glucose residues are then easily converted to alcohol and $\mathrm{CO}_{2}$ by yeast fermentation.

- Hemicelluloses (20\%-40\% by weight) are complex polysaccharides (xylans, mannans, glucans and galactans) made from a variety of 5- and 6-carbon sugars, which bind closely to cellulose strands, helping to "glue" them together. Xylanase enzymes can hydrolyze poly-xylans and so help to disrupt cell wall structure. 5-carbon sugars are not converted to ethanol by conventional yeast fermentation.

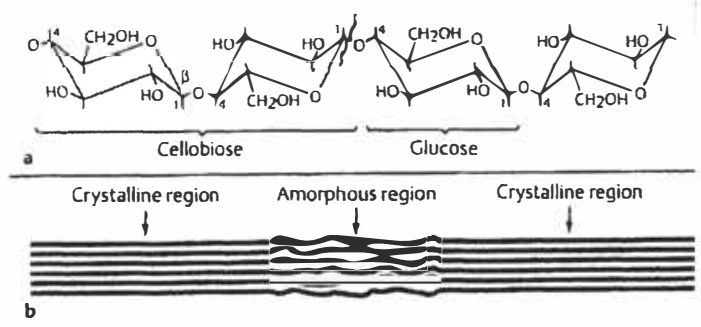

Figure 1. Cellulose: a: linear polymer of beta-linked glucose units; $b$ : micro-fibril structure 
- Lignin (10\%-24\% by weight, more abundant in woody plants) is a non-carbohydrate, aromatic, complex polymer, which provides structural integrity in plants. Lignin molecules form stable ester links with cellulose or hemicellulose strands, and protects from cellulase attack. Lignin remains after degradation of cellulose and hemicellulose components. The energy in residual lignin compounds could be utilised by combustion to provide process heat and electricity for the bio-refinery.

\subsection{The Industrial scale}

Production of ethanol from ligno-cellulosic material at the industrial scale must address the practical problems of

- Feedstock collection and delivery

- Pre-processing (size reduction),

- Pre-treatment (acid),

- Conditioning (e.g. steam "explosion" in a pressure vessel)

- Enzymatic hydrolysis

- Sugar fermentation

- Ethanol recovery and residual solids recovery.

If concentrated sulphuric acid is used as a pre-treatment in the SHF process, after the hydrolysis stage sugars for fermentation must be separated from the acid. A new ion exchange separation method of Arkenol (California), allows the acid to be concentrated and re-used [13], and final traces of acid are precipitated with lime. An advantage of SSF (patented by Gulf Oil and University of Arkansas) is to require fewer reactors, reducing capital costs [14]. It also avoids problems of enzyme inhibition arising from accumulating sugar products, because they are converted in situ into ethanol. The process has been further improved to enable co-fermentation of multiple sugar substrates (SSCF) [14].

Conventional yeasts cannot ferment 5-carbon sugars (mannose, xylose and arabinose) that arise from the hydrolysis of hemicellulose, but these may comprise $20 \%$ of the feedstock. Arkenol use specially bred yeast that feeds preferentially on C5 sugars, as well as on C6 sugars to enable a greater proportion of the feed to be utilised [13]. Another approach is to use the bacterium Zymomonas mobilis to metabolise C5 and C6 sugars to ethanol using the Entner-Doudoroff pathway.

Bio-refineries, in which plant waste materials are degraded to simple sugars, will exploit this "sugar platform" $[14,15]$ to produce, not only ethanol for fuel, but a range of building block chemicals (such as the organic acid lactate), by alternative enzymatic or fermentation processes. Conventionally derived from corn syrup by Cargill-Dow and Du Pont in the USA, lactate can be produced by fermentation of glucose syrup by lactic acid bacteria or fungi. The lactate monomer can then be purified and polymerised in various configurations into polylactic acid, which provides a biogenic alternative to commodity plastics (nylon, polypropylene, polyethylene, and polystyrene) derived from petrochemical based polymers. In the UK, the supermarket ASDA currently uses biodegradable plastic bags to demonstrate its green credentials, whereas research into high-value plastics for prosthetics and surgical implants is in progress.

A major barrier to exploitation of this emerging technology is the cost of enzyme production, but significant reductions have been made in recent years. Commercial development is most likely to be successful in areas where alternative disposal costs of agricultural wastes is high 
and burning is not permitted, and where there are conventional ethanol plants suitable for conversion. Similar considerations apply to utilisation of refuse-derived ligno-cellulosic material. This paper investigates the potential for processed domestic refuse to provide a sugar platform for the production of biogenic fuels (ethanol and hydrogen) and chemicals (lactate, butanol, acetone, fructose-rich sweeteners).

\subsection{Domestic refuse feedstock}

The need to utilise organic waste rather than disposal in landfill coincides with the need for reliable, low-cost feedstocks for cost-effective degradation of cellulose. Potential sources in the UK include agricultural crop residues, and cellulose pulp residue from paper making, but the use of refuse-derived material is particularly attractive for reasons of sustainability. A unique steam-pressure process recently developed by Davies Brothers (Cowbridge, South Wales) produces a dry, fibrous ligno-cellulosic material from domestic refuse. Raw waste material is packed into a tilted, rotating pressure vessel and incubated under steam pressure for 2 hours, after which liquor is drained off and the solid residue is processed to remove metals and any remaining large fragments. The steam-pressure process may provide a form of pre-treatment to "loosen" the molecular structure of ligno-cellulosic residues and facilitate enzyme activity. The potential of this material to yield simple sugars by enzymatic degradation was tested at laboratory scale. Similar procedures were used in previous trials with alternative feedstocks (wheat bran, biomass grass Miscanthus), in collaboration with Biocatalysts Ltd (Nantgarw, Mid-Glamorgan, Wales). Preliminary results are reported below.

\section{LABORATORY TRIALS: METHODS}

Reagents (obtained from Sigma-Aldrich unless stated)

- Dinitrosalicylic acid (DNS) solution: $200 \mathrm{ml} 2 \mathrm{M} \mathrm{NaOH}, 300 \mathrm{~g}$ potassium sodium tartarate, $10 \mathrm{~g}$ DNS, made up to $1000 \mathrm{ml}$ with Ultra-Pure water.

- $10 \mathrm{mM}$ sodium citrate buffier adjusted to $\mathrm{pH} 5$ with $1 \mathrm{M} \mathrm{NaOH}$.

- Cellulose azure (blue dye molecules attached to sugars by stable ester links).

Waste material processed by Davies Bros. was supplied in two "grades", before and after passing through a coarse screen to remove large solids (glass, bone,etc). The dried material resembled a grey-brown granular/fibrous soil. In the laboratory, both grades were passed through a $2 \mathrm{~mm}$ sieve and $1 \%$ suspensions prepared ( 5 g made up in $500 \mathrm{ml}$ of pH 5 sodium citrate buffer).

\section{Enzymes tested:}

- Cellulase, C013L (Biocatalysts Ltd); un-purified enzyme preparation (activity 1.5 $\mathrm{U} / \mathrm{mg}$ ) obtained by Trichoderma sp. fermentation.

- Ferulic Acid Esterase (FAE), Depol 740L (Biocatalysts Ltd); FAE breaks ester links between lignin and cellulose/hemicellulose strands.

- Purified Cellulase powders (Sigma-Aldrich) derived from:

\begin{tabular}{lll}
\hline Species of origin & Enzyme activity & Quantity for $50 \mathrm{U} / \mathrm{ml}$ solution \\
\hline Trichoderma viride & $7.8 \mathrm{U} / \mathrm{mg}$ & $6.41 \mathrm{mg}$ \\
\hline Trichoderma reesei & $6.3 \mathrm{U} / \mathrm{mg}, 9.4 \mathrm{U} / \mathrm{mg}$ & $7.94 \mathrm{mg}, 5.32 \mathrm{mg}$ \\
\hline Aspergillus niger & $1.3 \mathrm{U} / \mathrm{mg}$ & $38.46 \mathrm{mg}$ \\
\hline Aspergillus sp. & $1.0 \mathrm{U} / \mathrm{g}$ (liquid) & $240 \mu \mathrm{l}$ \\
\hline
\end{tabular}

Enzyme powders were made up to $50 \mathrm{U} / \mathrm{ml}$ standard solutions in $10 \mathrm{mM}$ sodium citrate buffier. 
Microcrystalline cellulose was used as a standard to check the activity of various cellulase enzymes in releasing glucose. Samples with varying enzyme concentrations, each with a total volume of $5 \mathrm{ml}$ were incubated in $50 \mathrm{ml}$ centrifuge tubes at $50{ }^{\circ} \mathrm{C}$ in a shaking incubator at 150 rpm. $100 \mu \mathrm{l}$ of the samples were taken, in triplicate, from the incubations and added to $900 \mu \mathrm{l}$ of $10 \mathrm{mM}$ sodium citrate buffer every $30 / 60$ minutes and to $3 \mathrm{ml}$ of DNS solution, before each sample was heated to $100 \mathrm{~h} C$ for $5 \mathrm{~min}$ in a heating block. After cooling to room temperature, the absorbance was measured at $540 \mathrm{~nm}$. Glucose concentrations were estimated using a preprepared standard curve, and hence the percentage of cellulose which had been hydrolysed.

As an alternative method of measuring enzyme activity, cellulose azure samples were incubated at $50 \mathrm{hC}$ with the different cellulases [16]. Absorbance was measured at $575 \mathrm{~nm}$, the intensity of colour indicating release of dye-attached cellulose molecules. The percentage of cellulose hydrolysed was estimated from a standard curve. The cellulose azure assay was used to investigate the effiect of possible product inhibition on the cellulases from Biocatalysts and Trichoderma viride. Cellulase incubations were made in the presence of $2.5 \mathrm{mM}$ and $5 \mathrm{mM}$ glucose, and separately with the same concentrations of fructose, and without added sugars. A combination of $0.1 \mathrm{ml}$ of glucose oxidase and $0.1 \mathrm{ml}$ catalase was added to cellulose azure incubations in order to remove glucose product by conversion to gluconic acid. A direct measure of cellulose degradation by $T$. viride cellulose was obtained from the mass of residual cellulose after 24-hour incubations, recovered by centrifuging at $4000 \mathrm{rpm}$ for 10 min, dried and weighed.

To estimate the yield of reducing sugars (RS) by degradation of the refuse-derived waste, samples of screened/unscreened waste suspension, and various cellulase enzymes, were added to sodium citrate buffier to a total volume of $20 \mathrm{ml}, 5 \mathrm{ml}$ or $6 \mathrm{ml}$ in different experiments. Mixtures were incubated at $50{ }^{\circ} \mathrm{C}$ for 2 hours, or up to 48 hours in some cases. Proportions of the components were varied to test the effects of enzyme concentration. Percentage degradation relative to the weight of crude waste material was estimated using the DNS assay on $1 \mathrm{ml}$ samples taken in triplicate from the incubations at varying times. Further incubations were carried out to test the combined effect of cellulase and FAE enzymes on the yield of RS. Waste suspensions were incubated initially with $\mathrm{C} 013 \mathrm{~L}$ or with $T$. viride (pure) cellulase, adding $0.5 \mathrm{ml}$ of FAE after 24 hours. This test was also made in reverse, incubating with FAE, followed by the cellulase enzymes.

\section{RESULTS}

\subsection{Micro-crystalline cellulose}

Biocatalysts' C013L cellulase (at dilutions of $30-40 \%$ of the supplied preparation), achieved degradation of around $90 \%$ after 24 hours incubation (50\% after 5 hours). Between-sample variability was large, with some apparent degradation rates over $100 \%$, indicating the presence of RS in the enzyme preparation, which masked the true level of glucose release from the cellulose. Trichoderma viride (pure) cellulase incubations showed more stable levels of glucose release (see Figure 2a), amounting to 100\% degradation after 24 hours (80-90\% after 5 hours). Diluting the enzyme preparation to $40 \%$ or below resulted in a markedly reduced rate of degradation (see Figure $2 a$ ). Enzymes from the other fungal species achieved lower rates of degradation than $T$. viride cellulase, determined by both the DNS and cellulose azure assays. There was no apparent inhibition of $T$. viride cellulase from either added glucose or fructose during short $(20 \mathrm{~min})$ incubations. In contrast, removal of glucose product with glucose oxidase and catalase resulted in almost twice the rate of degradation during a 20- 

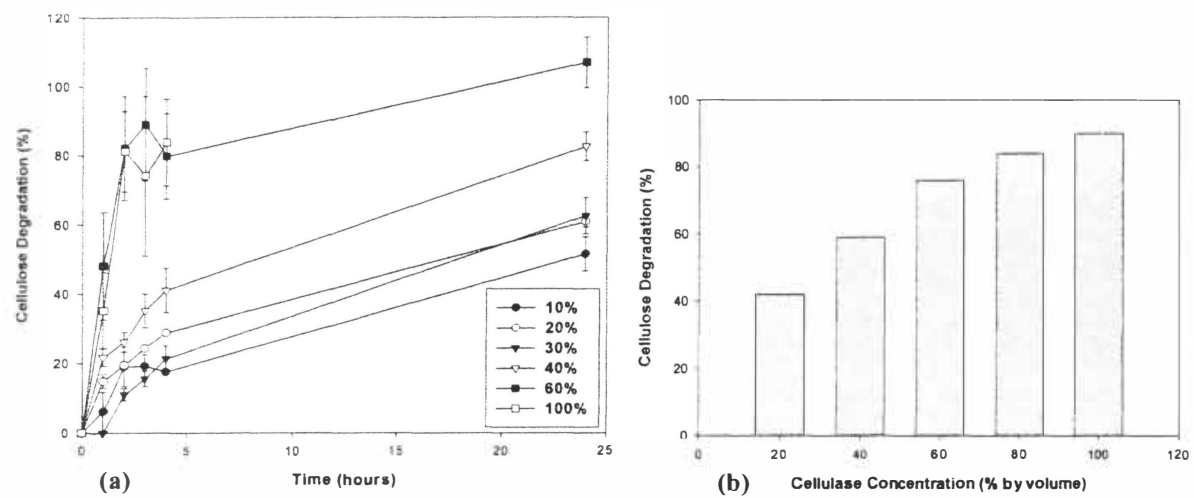

Figure 2. Cellulose degradation by T. viride cellulase at dilutions of 50U/ml stock, over 24 hours incubation; (a) DNS assay, (b) Residual cellulose by (weight).

minute incubation with $\mathrm{C} 013 \mathrm{~L}$ cellulase. The rate of degradation of micro-crystalline cellulose by $T$. viride cellulase is sensitive to enzyme concentration, as indicated by the weights of residual solid cellulose after incubation (see Figure $2 b$ ). About $90 \%$ degradation is achieved with full strength $(50 \mathrm{U} / \mathrm{ml})$ enzyme whereas at $60 \%$ dilution, almost $80 \%$ degradation occurred.

\subsection{Refuse-derived waste}

As with "pure" cellulose, Biocatalysts' C013L and T. viride cellulases both released RS from the refuse-derived waste more successfully than did the other fungal cellulases tested (see Figure 3). Conversion of waste mass into RS appeared to be low (13\% and $11 \%$ respectively) after 2 hours incubation of the screened material ( $8 \%$ and $5 \%$ of the unscreened waste). Diluting the cellulase enzymes below $60-80 \%$ of full strength markedly reduced their activity. Extending the incubation time to 48 hours with $T$. viride cellulase achieved conversion to glucose of only $8-9 \%$ by weight for the two types of waste (see Figure 4), whereas C013L gave up to $25-35 \%$ conversion after 24 hours (see Figure 5). In both cases, the majority of RS release occurred in the first 2 hours of incubation, with full enzyme concentrations.

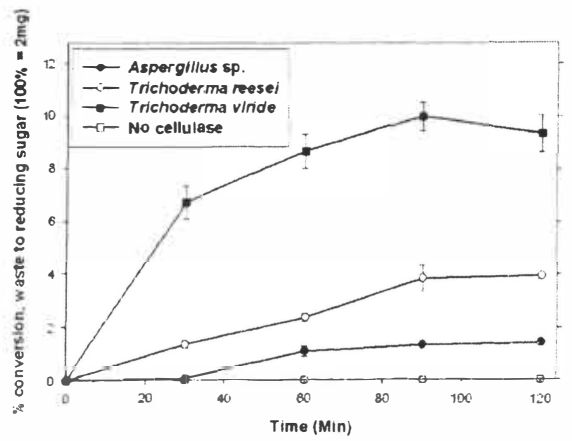

Figure 3. Conversion of waste to reducing sugars by 3 fungal cellulases over 2 hours. 


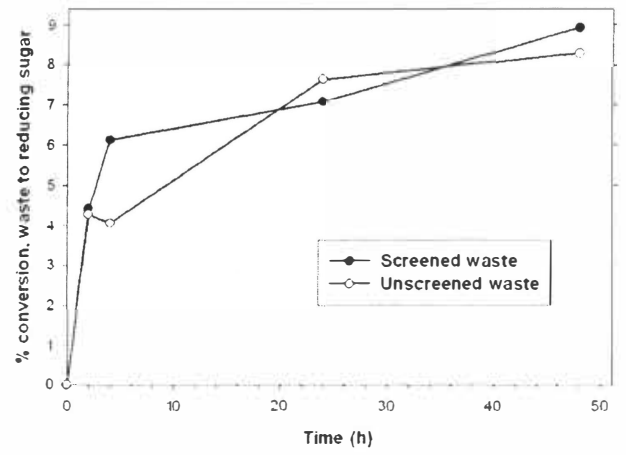

Figure 4. Conversion of waste to reducing sugars by T. viride cellulase over 48 hours.

Sequential digestions with Biocatalysts' C013L and FAE appeared to produce a greatly enhanced yield of RS from the waste samples. However, further tests indicated that reducing sugars were released rapidly in the incubation when cellulose and FAE were combined in the absence of waste material. This is explained by an interaction between cellulase and FAE (both as impure preparations), in which reducing sugars are released from polysaccharide present in one and/or the other preparation.

\section{DISCUSSION}

Micro-crystalline cellulose was almost completely degraded by both Biocatalysts' C013L and T. viride cellulases. Other Trichoderma and Aspergillus species enzymes performed less well. The rate of degradation apparently declined rapidly after 2-5 hours incubation, so that after 24 hours little more RS was released. Enzyme performance declined markedly when diluted in the incubation mixture. This indicates that the objective of reducing incubation time has to be balanced against minimising the quantity of enzyme used.

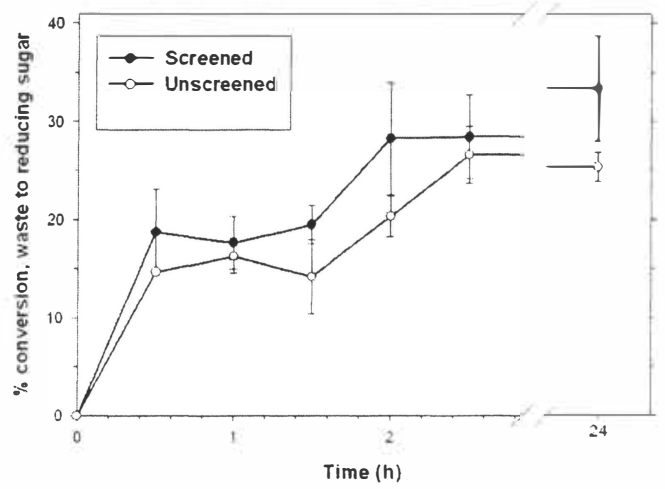

Figure 5. Conversion of waste to reducing sugars by Biocatalysts C013L cellulase over 24 hours. 
The commercial grade C013L cellulose (a crude preparation containing several enzymes), was successful in achieving up to $35 \%$ conversion of waste to RS in 2 hours. This is apparently much less than that achieved with "pure" cellulose. However, the initial cellulose content of the waste material is unknown, and is unlikely to be more than half its weight. Hence, an acceptable yield of sugar has occurred from a mixed waste substrate, without any form of pre-treatment. The "pure" $T$. viride cellulose achieved a much poorer apparent level of conversion, less than $10 \%$.

It was anticipated that FAE would be effiective in "loosening" the cellulose fibre structure by breaking ester linkages between ferulic acid of lignin molecules and hemicellulose xylan chains. Biocatalysts have recently developed Depol 740L FAE to enable complete breakdown of plant cell walls in the extraction of carrot and fruit juices, and in releasing fermentable sugars from barley grains in brewing. Pre-treating waste material with FAE prior to cellulose incubation may enhance its overall degradation, but any such effect was completely masked in our experiments by rapid release of sugars on mixing the two enzymes. Both were supplied as unpurified preparations, produced by fungal fermentation, containing residual substrate compounds. Further work is needed with purified FAE to assess its effectiveness for pretreatment of waste. As far as we are aware, the use of FAE is novel as an agent to enhance the effiectiveness of cellulase for biomass or waste hydrolysis in either SHF or SSCF regimes.

In a related research project, we investigated the conversion of the fructan carbohydrate, inulin (extractable from e.g. Dahlia, chicory and Jerusalem artichoke) to lactate, using thermostable enzymes obtained from thermophilic bacteria (Brevibacillus thermoruber and Geobacillus thermoleovorans), at reaction temperatures up to $95{ }^{\circ} \mathrm{C}$. A similar strategy, using thermostable enzymes, may be applicable to the saccharification of cellulose, by conducting the reaction at higher temperatures to avoid growth of contaminant organisms during the incubation. A quite different strategy to achieve degradation of cellulose could utilise the thermophilic anaerobic bacterium Clostridium thermocellum [12]. This organism uniquely possesses a "cellulosome" structure on the outside of the cell wall containing a complex of enzymes which can achieve efficient hydrolysis of cellulose at 60 hC. Growth of bacterial biomass, during incubation with waste material, could be prevented with an antibiotic. A subsequent stage of yeast fermentation could convert monosaccharides to ethanol.

Ultimately, commercial success of waste-to-energy conversions will depend not only on developing efficient biotechnological processes, but on minimising costs at all stages:- raw material handling, supply of enzymes and/or microbial agents, extraction of sugar products, and disposal of residues. In some cases these costs can be offiset with respect to alternative disposal costs of waste, creating a more favourable economic climate in which new waste-toenergy industries may develop.

\section{ACKNOWLEDGEMENTS}

We thank Andrew Way, James Arpino and Lucy Fay, who carried out laboratory work during summer 2005. The project was supported by Wales Waste \& Resources Research Centre, Cardiff University and the UK Landfill Tax Credit Scheme, administered through Cardiff Foundation for Environmental Research. We are grateful to Dr H.G. Williams, Biocatalysts Ltd, for providing enzymes C013L, Depol 740L, glucose oxidase and catalase. 


\section{REFERENCES}

[1] http://www.dti.gov.uk/energy/whitepaper/index.shtml

[2] Whitton P. 2005 Progressive Energy Ltd http://www.dti.gov.uk/energy/consultations/pdfs/ProgressiveEnergyLtdresponse.pdf

[3] UK wind energy database http://www.bwea.com/ukwed/

[4] Energy Power Resources http://www.eprl.co.uk/

[5] Khan I. 2005 "A Generator's View of Future Fuels" http://groups.iop.org/CB/events/fufpres/Iftikhar_Khan-RWE_npower.pdf

[6] Cardiff University "Refuse Derived Fuel" http://www.wasteresearch.co.uk/ade/efw/refuse.htm

[7] Plummer R. 2005. "The rise, fall and rise of Brazil"s biofuel" http://news.bbc.co.uk/1/hi/business/458 11955.stm

[8] Joshi S. Sakamoto O. \& MacLean H. "Economic Feasibility Analysis of Municipal Solid Waste to Ethanol Conversion"

http://www.eere.energy.gov/biomass/biotech_symposium/docs/la-16.doc

[9] Elander R. 2002. "Ethanol from cellulosic materials" http://www.hawaii.gov/dbedt/ert/ethanol-workshop/09-Elander-colordistilled.pdf

[10] Chen C. "Biomass for ethanol and cropping systems for bioenergy" http://www.harvestcleanenergy.org/conference/HCE5/HCE5_PPTs/Chen.pdf

[11] US Dept. of Energy "Bioethanol Feedstocks" http://www.eere.energy.gov/biomass/abcs_biofuels.html\#prod

[12] Lengeler JW, Drews G,Schlegel HG (Eds) 1999. Biology of the Prokaryotes. Blackwell.

[13] "Greener Industry, ethanol issues" http://www.uyseg.org/greener_industry/pages/ethanol/ethanol7PM2.htm

[14] US Dept. of Energy "Biomass Programme" http://www.eere.energy.gov/biomass/

[15] "Cellulosic Ethanol" http://www.ethanolrfa.org/resource/cellulosic/

[16] Ng TK \& Zeikus JG 1980. Analytical Biochem. 103, 42-50 